\title{
GESTÃO DEMOCRÁTICA NA EDUCAÇÃO INFANTIL
}

\author{
GESTIÓN DEMOCRÁTICA EN LA EDUCACIÓN INFANTIL
}

DEMOCRATIC MANAGEMENT IN CHILD EDUCATION

\author{
Leandra Fernandes do NASCIMENTO ${ }^{1}$ \\ Maria Marina Dias CAVALCANTE ${ }^{2}$
}

RESUMO: A Gestão Democrática foi aplicada na Educação Infantil, recorrendo-se aos seus diversos instrumentos legais. O objetivo deste estudo foi conhecer o processo de Gestão Democrática na Educação Infantil. Adotou-se a abordagem de pesquisa qualitativa, delineando-a em estudo de caso, a fim de permitir ao pesquisador conhecer e refletir sobre o contexto teórico e prático da gestão na escola. Verificou-se que essa temática é caracterizada pela efetiva participação de todos os envolvidos no processo educacional e que essa etapa da educação vem passando por diversas transformações nas últimas décadas, sendo amparado por vários dispositivos legais, a fim de melhorar o trabalho. Conclui-se que somente a efetiva participação dos agentes da comunidade escolar, em parceria com os órgãos públicos, será capaz de superar os desafios educacionais.

PALAVRAS-CHAVE: Educação infantil. Gestão democrática. Ambiente escolar. Comunidade escolar.

RESUMEN: La gestión democrática se aplicó en la educación infantil, utilizando sus diversos instrumentos jurídicos. El objetivo de este estudio fue conocer el proceso de gestión democrática en la educación infantil. Se adoptó el enfoque cualitativo de la investigación, que lo esbozaba en caso de estudio con el fin de permitir al investigador conocer y reflexionar sobre el contexto teórico y práctico de la gestión en la escuela. Se ha comprobado que esta temática se caracteriza por la participación efectiva de todos los involucrados en el proceso educativo y que esta etapa de la educación ha estado atravesando varias transformaciones en las últimas décadas, siendo apoyado por diversos dispositivos jurídicos para mejorar el trabajo. Se concluye que sólo la participación efectiva de los agentes de la comunidad escolar, en asociación con los órganos públicos, será capaz de superar los desafíos educativos.

PALABRAS CLAVE: Educación infantil. Gestión democrática. Ambiente escolar. Comunidad escolar.

1 Doutoranda em Educação - UECE/PPGE - Universidade Estadual do Ceará. E-mail: leandrafn@yahoo.com.br

${ }^{2}$ Professora Efetiva da UECE/PPGE - Universidade Estadual do Ceará. E-mail: maria.marina@uece.br 
ABSTRACT: The Democratic Management was applied in Early Childhood Education, using its various legal instruments. The objective of this study is to know the process of Democratic Management in Early Childhood Education. The qualitative research approach was adopted, delineating it in a case study, in order to allow the researcher to know and reflect on the theoretical and practical context of the management in the School. It was verified that Democratic Management in Early Childhood Education is characterized by the effective participation of all those involved in the educational process and that this stage of education has undergone several transformations in the last decades, being supported by several legal devices, in order to improve the work. It is concluded that only the effective participation of the agents of the school community, in partnership with public agencies, will be able to overcome the educational challenges.

KEYWORDS: Early childhood education. Democratic management. School environment. Community school.

\section{Introdução}

Como um marco intelectual para a sociedade, este estudo aborda a Gestão Democrática na Educação Infantil e suas vertentes. A pesquisa realiza uma abordagem qualitativa, que busca conhecer o processo de gestão a ser adotado nas instituições de ensino, levando os gestores, educadores e interessados na gestão escolar e na educação, a pensar e refletir sobre a sua atuação, sua contribuição na gestão desses ambientes educacionais, os desafios que se tem em implantar uma gestão democrática, a importância de se implantar uma gestão baseada na participação de todos os envolvidos na educação e também o desenvolvimento e aprendizagem das crianças.

A Educação Infantil é uma etapa da Educação Básica, onde as Instituições de Educação são responsáveis pela organização de projetos, por providências administrativas, técnicas e políticas, ou seja, uma forma própria de organização. Conhecer os elementos básicos que contribuem para as instituições funcionarem baseadas em um processo democrático é essencial para que se desenvolva um bom trabalho educacional nas Instituições de Educação Infantil.

Na legislação educacional brasileira, a educação da criança de 0 a 5 anos de idade é definida como a primeira etapa da Educação Básica e está integrada ao sistema de ensino (LDBEN 9394//96). Sendo assim, as Instituições de Educação Infantil pública ou privada devem ser criadas e regidas de acordo Art. 206, VI, Constituição, 1988. A Gestão Escolar pode ser mais ou menos participativa, e a participação dos diferentes 
atores do processo educacional deve contribuir para a melhoria da qualidade do trabalho no interior da escola.

Desse modo, centra-se na perspectiva da Educação Infantil de crianças de 4 e 5 anos de idade, tendo por objetivo conhecer o processo de Gestão Democrática na Educação Infantil. Isso significa trazer para o debate quais os atores que contribuem para a efetivação do processo de gestão democrática nas instituições de Educação Infantil.

Diante do exposto a pesquisa se caracteriza pela abordagem qualitativa, busca apresentar um caráter exploratório, entender um fenômeno específico através de dados, contextos e técnicas de interpretação e enfatizar o fenômeno descrevendo a realidade.

O estudo aborda três objetivos específicos que são, analisar os limites e possibilidades no processo da Gestão Democrática na Educação Infantil, explicar de que maneira essa gestão é aplicada e analisar como os agentes envolvidos podem contribuir com a Gestão Democrática na Educação Infantil.

\section{A educação infantil}

A educação é responsável pela aquisição, atualização e utilização dos conhecimentos. Sendo ela oferecida em estabelecimentos de ensino, deve ter o seu tempo todo voltado para aquisição da aprendizagem dos seus educandos. Saviani (1991, p.19) diz que: “a educação é um fenômeno próprio do ser humano, ou é um ato humano por excelência".

“[...] A educação infantil é uma etapa regida, portanto, pelos princípios e fins da educação brasileira, os quais expressam os grandes ideais e valores da nação sobre a educação dos seus cidadãos" (BRASIL, 2005a, p, 19).

Art. $5^{\circ}$ A Educação Infantil, primeira etapa da Educação Básica, é oferecida em creches e pré-escolas, as quais se caracterizam como espaços institucionais não domésticos que constituem estabelecimentos educacionais públicos ou privados que educam e cuidam de crianças de 0 a 5 anos de idade no período diurno, em jornada integral ou parcial, regulados e supervisionados por órgão competente do sistema de ensino e submetidos a controle. (RESOLUÇÃO No 5, DE 17 DE DEZEMBRO DE 2009)

De acordo com as Diretrizes Curriculares Nacionais para a Educação Infantil (resolução $\mathrm{n}^{\circ} 5$, de 17 de dezembro de 2009, "é obrigatório a matrícula na educação 
infantil de crianças que completam 4 ou 5 anos de idade até o dia 30 de março do ano em que ocorrer a matrícula". Estabelecendo uma mudança em relação à idade (que antes era de seis anos e passa ser agora de cinco anos) e a obrigatoriedade da inserção das crianças na pré-escola.

Em abril de 2013, passou a vigorar a nova lei que engloba a Educação Infantil e representa mais uma conquista em favor do desenvolvimento intelectual e social das criança. Essa lei de ${ }^{\circ} 12.796$, de 4 de abril de 2013, alterou a Lei de Diretrizes e Bases da Educação de 1996, aprovando novas emendas constitucionais, nas quais estabelece:

Art. $4^{\circ}$, I educação básica obrigatória e gratuita dos 4 (quatro) aos 17 (dezessete) anos de idade, organizada da seguinte forma:

a) pré-escola;

b) ensino fundamental;

c) ensino médio;

II - educação infantil gratuita às crianças de até 5 (cinco) anos de idade

Art. $6^{\circ}$ É dever dos pais ou responsáveis efetuar a matrícula das crianças na educação básica a partir dos 4 (quatro) anos de idade. (LEI $\left.\mathrm{N}^{\circ}-12.796,2013\right)$

Há vários instrumentos legais, garantindo os direitos de cidadania das crianças brasileiras de 0 aos 6 anos, dentre os quais destacamos:

a- Constituição Brasileira de 1988;

b- Lei de Diretrizes e Bases da Educação Nacional - LDB (Lei 9394/96);

c- Diretrizes Curriculares Nacionais para a Educação Infantil - (DCNEI/99)

Parecer

CEB/CNE nº. 22/98, aprovado em 17/12/98, Resolução CEB/CNE no 1/99.

Diário Oficial, Brasília, 13/4/99, Seção 1, p.18;

d- Estatuto da Criança e do Adolescente - ECA (Lei 8069/90);

e- Lei Orgânica da Assistência Social - LOAS (Lei 8742/93);

f- Convenções Internacionais;

g- Constituições Estaduais e Leis Orgânicas Municipais.

Visando desenvolver um acompanhamento e um bom trabalho nas instituições foram criados vários documentos que orientam a prática pedagógica nos estabelecimentos de ensino, com informações que subsidiam no desenvolvimento da ação educativa na educação infantil.

O currículo da Educação Infantil propõe ações pedagógicas específicas para crianças na faixa etária de 0 a 5 anos de idade. Subsidiando e orientando ações pedagógicas para trabalhar no cotidiano da Educação Infantil. Nas Diretrizes Nacionais 
Curriculares para a Educação Infantil de 2010, citam diversas áreas em que as ações pedagógicas estão voltadas, como em relação às: especificidades do bebê; o brinquedo e brincadeira; as relações entre adultos e crianças; as múltiplas linguagens dos meninos e meninas; como em relação à saúde e o bem estar das crianças nesse ambiente; a linguagem escrita e o direito a educação nos primeiros anos de idade; a criança e o conhecimento matemático; criança e a natureza; orientações curriculares para a criança no campo; assim como a avaliação e transição na Educação Infantil.

As Propostas Pedagógicas ou Projeto Político Pedagógico é o plano orientador das ações da instituição de ensino e deve garantir que se cumpra plenamente sua função sociopolítica e pedagógica. Respeitando os princípios éticos, políticos e estéticos.

O artigo 37 da Constituição de 1998 fixou os princípios de legalidade, impessoalidade, moralidade, publicidade e eficiência (...) para a administração publica dos poderes da União, dos estados, do Distrito Federal e dos Municípios. Para Cury (2002, p.98b) esses dispositivos, “(...) se e quando efetivados, colocam a transparência, o diálogo, a justiça e a competência como transversais à cidadania democrática e republicana”.

\section{A Gestão Democrática Nos Primeiros Anos de Aprendizagem}

O Art. 14, LDBEN 9394/96 define que a democratização da gestão educacional no Brasil não se constitui hoje, opção de governantes e administradores, é antes, compromisso socialmente constitucionalmente estabelecido.

Para Libâneo (2004), a gestão democrática-participativa valoriza a participação da comunidade escolar no processo de tomada de decisão, insere a docência como trabalho interativo, permitindo a construção coletiva dos objetivos e funcionamento da escola, por meio da dinâmica intersubjetiva, do diálogo e do consenso.

\footnotetext{
A gestão escolar deve articular e considerar todas as pessoas envolvidas com a educação em cada instituição de ensino. O trabalho de uma gestão escolar deve apostar na possibilidade de participação e envolvimento de todos (BRASIL, 2OO5c, p14).
}

A democracia defendida por Touraine (1998) é uma democracia social, que se coloca "no plano dos atores sociais e não acima deles e procura estabelecer a justiça, ou seja, assegurar antes de mais nada, o acesso dos dominados à ação, à influencia e ao poder político" (Touraine, 1998, p.47). 
Um gestor democrático faz da escola um ambiente acolhedor, respeita a opinião dos outros, aceita a opinião da maioria, delega poderes e responsabilidades aos outros parceiros para compartilhar as funções da escola.

São necessários objetivos educacionais e de gestores que facilitem esse processo da gestão democrática. Pois, segundo Luck (2000) um gestor comprometido:

Cria ambientes participativos, cria uma visão de conjunto associada a uma ação de cooperativismo, promove um clima de confiança, valoriza as capacidades e aptidões dos participantes, associa esforços, quebra arestas, elimina divisões e integra esforços, estabelece demanda de trabalho centrado nas idéias e não em pessoas desenvolve a prática de assumir responsabilidades em conjunto (LUCK, 2000, p.18).

Essa ideia de Luck (2000) reafirma as características de um gestor democrático comprometido. Ele se faz presente em todas as situações que envolvem o cotidiano da escola, incentivando e de certa forma liderando, para que os todos os agentes se façam presentes, participando, interagindo e criando um ambiente que tenha as características da comunidade local, e realizando junto um trabalho educacional de qualidade.

\section{O Modelo de Gestão}

O novo modelo de gestão escolar propõe a construção de instituições autônomas com a capacidade de tomar decisões, elaborar projetos institucionais vinculados a necessidade e aos interesses da comunidade, administrar de forma adequada os recursos e materiais e escolher estratégias que lhe permitam chegar aos resultados desejados. Que em seguida serão avaliados (BRASIL, 2006c, p.19).

Esse modelo possibilita as escolas trabalharem em cima de suas necessidades e prioridades, definindo um melhor desenvolvimento de suas ações, com base nos seus objetivos mais urgentes. Libâneo et al (2007) reforça essa ideia quando diz que:

A organização escolar entendida como comunidade democrática de aprendizagem transforma a escola em lugar de compartilhamento de valores e de práticas, por meio do trabalho e da reflexão conjunta sobre planos de trabalho, problemas e soluções relacionados à aprendizagem dos alunos e ao funcionamento da instituição (LIBANEO et al, 2007, p.316).

Assim como diz Marschal (1967, p. 73), “a educação é um pré-requisito necessário da liberdade civil, e como tal, uma pré-condição do exercício de outros direitos". Formar 
cidadãos significa formar pessoas inteligentes que sabem agir diante de contextos sociais. O mesmo autor também escreveu que "a educação das crianças está diretamente relacionada com a cidadania, e, quando o Estado garante que todas as crianças serão educadas este tem em mente, sem sombra de dúvida, as exigências e a natureza de cidadania" (ibidem).

A ação impositiva e autoritária não deve marcar a educação que queremos desenvolver hoje na sociedade.

Para que haja educação na escola, é necessário que as pessoas se conscientizem de que uma instituição educacional não deve ser um espaço para o exercício do poder, mas sim um lugar onde as pessoas se unem em torno dos objetivos comuns (BRASIL, 2006c, p. 21-22).

Gestão Democrática da Educação (assim como está escrito na Constituição Federal 1988 no Art. 37) é regida pela: transparência e impessoalidade, autonomia e participação, liderança e trabalho coletivo, representatividade e competência. Voltada para um processo de decisão baseada na participação e na deliberação pública. Visando o crescimento dos cidadãos na sociedade.

A gestão democrática antes de tudo é uma abertura ao diálogo e à busca de caminhos mais consequentes para a democracia da escola brasileira em razão aos seus fins maiores postos no Art. 205 da Constituição Federal.

Gestão Democrática caracteriza um regime onde seres sociais procuram estabelecer justiça entre o acesso aos direitos e ao poder, ela é estabelecida quando a maioria ganha o poder de representatividade. Essa é uma das regras que Bobbio (2000) apresenta como condição para a democracia. As outras são exigências de participação, de um número elevado de sujeitos no processo de tomada de decisões, devem ser as condições mais próximas possíveis do ideal para tais procedimentos (BOBBIO, 2000, p.31-32).

Para Lima (2000, p. 19), a democratização escolar é:

Uma perspectiva conceptual que focaliza intervenções democraticamente referenciadas, exercidas pelos atores educativos e consubstanciadas em ações de (auto) governo; ações que não apenas se revelam enquanto decisões politicas-administrativa tomadas a partir de contextos organizacionais e de estruturas de poder de decisão, mas que também interferem na construção e recriação dessas estruturas e de forma mais democrática de exercer os poderes educativos no sistema escolar, na sala de aula, etc. 


\section{Gestão Democrática No Brasil}

A Constituição da República Federativa do Brasil de 1988, no Art. 206, inciso VI, estabelece gestão democrática como um dos princípios da educação. Esses princípios abrangem e consolidam as dimensões pedagógica, administrativa e financeira das unidades educacionais.

A LDBEN 9394/96 estabelece como principio em seu Art. $3^{\circ}$, inciso VII, "a gestão democrática do ensino público, na forma da lei e da legislação dos sistemas de ensino". O Art. $14^{\circ}$ de certa forma complementa esse artigo declara que "os sistemas de ensino definirão as normas de gestão democrática de ensino público na educação Básica, de acordo com suas peculiaridades".

O princípio da autonomia requer vínculos mais estreitos com a comunidade educativa, basicamente os pais, as entidades e organizações paralelas a escola. A presença da comunidade na escola, especialmente dos pais, tem várias implicações. Prioritariamente os pais e outros representantes participam do Conselho da Escola Associação de Pais e Mestres para preparar o projeto político pedagógico curricular e acompanhar e avaliar a qualidade dos serviços prestados (LIBÂNEO, 2004, p.144).

No Inciso II do Art. 14 da LDBEN 9394/96 estabelece como principio para a efetivação da gestão democrática a participação da comunidade escolar e local em conselhos escolares ou equivalentes.

Os conselhos, colegiados e comissões, objetivam construir processo de discussão e análise do contexto escolar... O conselho como forma de organização participativa da equipe pedagógica, pode ser compreendido como um espaço onde se desenvolve a reflexão sobre a origem, encaminhamentos e consequências das questões relativas ao dia a dia da escola, permitindo a compreensão estrutural dos aspectos institucionais, análise da complexidade da realidade local e como essa realidade interfere no fazer pedagógico (BRASIL, 2006c, p. 28).

\section{Limites e Possibilidades}

Uma escola unida e organizada facilita a luta por melhores condições de desenvolvimento da educação, tanto nos aspectos estruturais, materiais como profissionais. 
Vale ressaltar a importância dos membros do conselho na efetivação da gestão democrática, a partir de uma visão mais abrangente e cooperativa, o Conselho Escolar pode ser compreendido como uma instancia de decisão colegiada com a função de gerir a escola democraticamente, representando os diferentes segmentos da comunidade escolar com o papel na construção do seu projeto político-pedagógico; em sua implantação, acompanhamento e avaliação sistemática (BRASIL, 2006c, p. 28).

Oliveira (1997) cita a eleição direta na escola como uma forma democrática de gestão e uma abertura para a participação quando fala que:

As eleições diretas representam a possibilidade de introduzir certos elementos horizontalizados de uma relação cristalizada de cima para baixo. Porque ela não só permite como necessita de participação de todos, sem a qual não é possível prosseguir, pois lhe falta legitimidade. É nessa busca de autorização, de respaldo, que os portadores das condições últimas para gerir a escola vão refletir sobre os demais segmentos que a compõem (OLIVEIRA. 1997, p.108).

A participação na gestão escolar proporcionará a seus atores um melhor conhecimento sobre as atividades desenvolvidas na escola, sobre o seu funcionamento, sobre novos rumos que devem ser estabelecidos para se desenvolver na pratica uma educação de qualidade, que atenda aos interesses do seu público alvo.

A participação é o principal meio de se assegurar a gestão democrática da escola, possibilitando o envolvimento de profissionais e usuários no processo de tomada de decisões e no funcionamento da organização escolar. Além disso, proporciona um melhor conhecimento dos objetivos e metas, da estrutura organizacional e de sua dinâmica, das relações da escola com a comunidade, e favorece uma aproximação maior entre professores, alunos, pais (LIBÂNEO, 2004, p.79).

Assim, compreende-se que para se desenvolver uma gestão democrática, faz-se necessariamente importante e preciso a participação de representantes de todos os segmentos da escola, nas decisões e ações desenvolvidas na escola.

A democratização da gestão educacional no Brasil é um compromisso constitucionalmente estabelecido do Estado e da sociedade. (Art. 14 da LDBEN 9394/96). É uma forma de buscar ações que visem transformar o espaço educacional, a partir de orientações que surgem de um grupo da escola, a fim de envolver os demais integrantes do ambiente no processo educativo, a fim de conquistar a educação que 
atenda a todas as necessidades dos educandos, ou mais amplamente de toda a comunidade escolar.

O conceito de educação supera o de administração, pois se "assenta na mobilização do elemento humano, coletivamente organizado, como condição básica e fundamental da qualidade de ensino e da transformação da própria identidade das escolas" (LUCK, 2007, p. 27).

Todos devem participar e exercer seus direitos e deveres, compromissados a atingir os objetivos definidos coletivamente. Silva (2004, p. 82-83) esclarece algumas formas do processo de trabalhos em escolas democráticas:

- A organização do trabalho pedagógico na escola está intrinsecamente relacionada à organização da sociedade que reflete no seu interior as determinações e contradições inerentes ao modelo capitalista;

- A escola de qualidade exige ruptura com privilégios de minoria econômica, não se restringindo apenas a provimentos de recursos metodológicos porque a garantia de qualidade está atrelada as decisões das políticas social e educacional nas múltiplas determinações;

- A garantia do acesso da permanência e do sucesso do aluno na escola não se define no seu limitado espaço interno;

- A prática democrática comprometida com a qualidade do ensino não é autônoma em face das condições reais de exigências impostas a seus sujeitos.

Nesse sentido, a participação é entendida como necessária, já que a interação, respeitando-se a peculiaridades de cada instituição, entre a família e a escola permitiria um mútuo acompanhamento e, ainda uma troca de experiências que poderia enriquecer as possibilidades de ação junto às crianças.

Estudar um pouco da história da Educação Infantil significa chegar mais perto dos momentos dos quais os homens e mulheres criaram lugares para cuidar, para escolarizar, enfim, para receber as crianças. As formas que tais instituições assumiram em diferentes situações muitas vezes se relacionaram com idéias de ordem, progresso e prosperidade (e assim por diante) produzidas de diversas formas pela sociedade. Com isso se quer dizer que na história das creches, dos jardins-de-infância e das pré-escolas encontra-se também a história do trabalho, de quem trabalha e de quem manda trabalhar. Acha-se também a história das pessoas que encontraram no cuidado da criança uma profissão, um lugar para construir a própria identidade (BRASIL, 2006b, p. 16). 
Porém, pensar que somente os filhos das mães que trabalham devem frequentar as instituições de Educação Infantil é um pensamento anacrônico, num mundo em que a institucionalização da infância e o direito a educação vem desde cedo, ou seja, mesmo antes de nascer.

\begin{abstract}
Um dos primeiros desafios a serem enfrentados é garantir a concepção de Educação Infantil, construída no Brasil nos últimos 30 anos, baseada na defesa de uma educação que não reproduza desigualdades de classe, gênero, e etnia/cor. $\mathrm{O}$ acesso às creches e pré-escolas, concebidas como instituições educacionais, não está dissociado de uma oferta de qualidade, em espaços institucionais não domésticos, com infraestrutura adequada e com profissional qualificado, sustentando-se numa concepção de sujeito de direitos e produtora de cultura (VIEIRA, 2011, p 248).
\end{abstract}

Conceber a Educação Infantil como uma importante ação para as crianças e desenvolvê-la com qualidade é um desafio que só será superado quando todos se sentirem comprometidos e responsáveis para que tal processo aconteça.

A LDBEN N 9494/96 mesmo sem definir claramente a adoção de um regime democrático, foi a que mais favoreceu a criança pequena, tornando a Educação Infantil uma formação contínua e parte integrante da Educação Básica brasileira. Ela declara na Educação Infantil uma divisão por idade (de 0 a 3 anos, creche; e, de 4 a 5 anos na préescola). Embora essa divisão tenha ocasionado mais um desafio a ser solucionado ainda nos dia atuais.

A Educação Infantil segundo o Art. 29 da LDBEN tem como finalidade o desenvolvimento integral da criança. Nesse ponto se gera mais um grande desafio de consolidar esses aspectos sem antecipar etapas da vida da criança e trabalhá-los sem imposição, mas sim de forma lúdica e prazerosa. O desafio da Educação Infantil está justamente aí, pois ela deve responder a duas tarefas:

Garantir os direitos das crianças, no presente no seu cotidiano, respeitando as características e necessidades de sua faixa etária, favorecendo o seu desenvolvimento afetivo, cognitivo cultural; ajudar na formação de uma nova geração que seja capaz de viver e contribuir para melhorar a vida de um mundo cada vez mais complexo, cheio de contradições e conflitos e ameaçados em sua sobrevivência enquanto suporte para a vida humana e de outras espécies de vida (BRASIL, 2005a, p. 38).

A aceitação de crianças pequenas se desenvolverem em ambientes escolares está se dando de forma gradativa. Na atualidade, grande parte da população aceita e deseja 
que as crianças pequenas frequentem a pré-escola, porém ainda há grandes restrições à inclusão de crianças menores de três anos em creches.

Com o aumento da demanda, aumenta também os recursos econômicos para as instituições serem administradas. Nesse sentido, Campos et al (2011) afirmam que “[...] para serem, minimamente satisfatórias, as creches exigem recursos maiores do que aqueles previstos pelo FUNDEB. Tanto para implementação como para a sua manutenção [...]" (CAMPOS et al, 2011, p. 205). Faz-se necessário um equilíbrio entre a demanda e os recursos.

Outro aspecto que deve ser enfrentado está em relação à formação e valorização do professor (a) da Educação Infantil. "[...] O conflito da Identidade desses (as) profissionais, caracteriza-se pela cumplicidade e a fragilização da concepção de Educação Infantil, como primeira etapa da Educação Básica" (CAMPOS et al, 2011, p.207). Essa tensão aumenta quando o município contrata profissionais sem formação e que não recebem o piso salarial, mas que desempenham uma função docente.

Para se desenvolver um trabalho de qualidade na educação, faz-se necessário, professores bem formados e renumerados para que assim, possa se ter um desenvolvimento satisfatório do seu trabalho. "O preconceito com as crianças pequenas e os/as profissionais que com elas trabalham, só pode ser combatidos com a exigência de qualidade para a Educação Infantil” (CAMPOS et al, 2011, p.208).

A formação de professores em nível superior para a Educação Infantil faz-se necessário, as crianças não precisem conviver com pessoas adultas de pouca formação escolar. "[...] A qualificação de professores e professoras é um direito de todas as crianças" (CAMPOS et al, 2011, p. 214).

Uma das metas do novo Plano Nacional da Educação (PNE, 2010) é oferecer o atendimento a $50 \%$ e assegurar a matrícula de todas as crianças na faixa etária de quatro a cinco anos de idade na Pré-escola.

O Plano Nacional da Educação (2010) propõe novas metas para melhorar o atendimento na Educação Infantil quando estabelece que:

Art. $2^{\circ}$ São diretrizes do PNE - 2011/2020:

II - universalização do atendimento escolar;

III - superação das desigualdades educacionais;

IV - melhoria da qualidade do ensino;

V - formação para o trabalho; 
Durante muito tempo os pais e o grupo social a que a criança pertencia, era responsável pela educação das crianças, por meio de trocas de experiências.

As famílias muito pobres, em sua maioria eram consideras incapazes de educar suas crianças. Portanto, as escolas nas décadas de 1920 e 1930 utilizavam a escola como espaço para a higienização das famílias.

Os administradores das creches pretendiam educar as mães para o apaziguamento social (...). A creche não educaria apenas as mães, mas também as crianças, formando-as desde berço, para se adaptarem a sociedade, satisfeitas com seu destino (KUHLMANN JR., 1988, p. 184).

Como está escrito na LDBEN - Lei de Diretrizes e Bases da Educação Nacional $n^{\circ}$ 9394/96, a Educação Infantil tem a finalidade de promover o desenvolvimento da criança, complementados a ação da família e da comunidade.

A Constituição de 1988, no seu Art. 208, inciso IV, define de forma clara, a responsabilidade do Estado para com a educação de crianças de zero a seis anos de idade, sendo entendida como não obrigatória e compartilhada com a família.

As legislações complementares que se seguiram- o Sistema Único de Saúde (SUS), o Estatuto da Criança e do adolescente (ECA), a Lei Orgânica de Assistência Social (LOAS) e a Lei de Diretrizes e Bases da Educação (LDBEN) - todas produzidas nos primeiros anos da década de 90, alem de reiterarem os direitos das crianças, pequena a educação, consagram o principio da descentralização administrativa com ênfase no papel do município e na parceria da sociedade civil, o que se expressou na criação dos diversos conselhos, com o principio da democracia participativa (BRASIL, 2006a, p. 21).

Aos municípios é atribuída à responsabilidade de administrar a Educação Básica (onde está incluso a Educação Infantil), em colaboração com os Estados e União. Responsabilidade instituída no artigo $8^{\circ}$ e $11^{\circ}$ da Lei de Diretrizes e Bases da Educação. Pode-se citar também como exemplo, a aprovação do Fundo de Manutenção e Desenvolvimento da Educação Básica e de Valorização dos Profissionais da Educação (FUNDEB), em vigor desde 2007 (aprovada pela emenda constitucional n 53, de 2006 e regulamentada pela Lei $\mathrm{n}^{\circ} 11.494$, de 2007 e pelo decreto $\mathrm{n}^{\circ} 6.253$, de 2007), com previsão de se estender até o ano de 2020.

O FUNDEB tem como intenção manter a Educação Básica, implementando mecanismo de valorização de todos os profissionais do magistério e conseguir reais 
avanços na qualidade do ensino. O FUNDEB, ao reconhecer a Educação Infantil como parte da Educação Básica trouxe grandes avanços em relação ao financiamento, principalmente em relação ao valor atribuído às creches.

A emenda constitucional 59/2009 alterou a obrigatoriedade educacional para a educação de 4 a 17 anos, englobando a Educação Infantil, o Ensino Fundamental e o Ensino Médio, antes restrito somente ao Ensino Fundamental.

Houve, também, ações para ampliação da oferta da Educação Infantil, como a garantia do atendimento aos educandos, por meio de Programas suplementares de material didático escolar, transporte alimentação e assistência à saúde e a formação de professores. Pode-se citar como exemplo nesse caso o Proinfância (Programa Nacional de Reestruturação e Aparelhagem da Rede Escolar Pública de Educação Infantil) que faz parte do Plano de Desenvolvimento da Educação (PDE). Os recursos desse Programa são destinados à construção, melhoria da infraestrutura, reestruturação e aquisição de equipamentos para creches e pré-escolas públicas da Educação Infantil.

As novas leis que surgiram vieram mostrar que a população vem reivindicando os direitos Constitucionais e também mostrar a necessidade de fortalecer a Educação Infantil.

A participação da sociedade civil organizada tem contribuído para a materialização de políticas e demais lutas por uma educação de qualidade. Desde 1990, existe a organização de fóruns de Educação Infantil nos municípios e estados brasileiros, conhecidos como MIEIB.

É preciso lembrar que o MIEIB, foi criado com a finalidade de articular força na sociedade para garantir essa efetivação dos direitos das crianças de 0 a 6 anos de idade. Ele constitui uma iniciativa da sociedade que se organizou através de órgãos e instâncias representativas para lutar em defesa das oportunidades de atendimento, as mais amplas possíveis, às crianças pequenas (BRASIL, 2005e p. 27).

Apesar de grandes avanços na Legislação, nas Diretrizes Curriculares e nas fontes de financiamento, ainda existe uma distância entre o previsto e o promovido pelos municípios que são em maior parte responsáveis pela gestão da Educação Infantil. Campos et al (2011) relatam que mobilizações para exigir uma educação de qualidade são importantes e que devem ser incentivadas. "É importante esclarecer o público, para que possam julgar a qualidade do atendimento, mobilizar-se cobrando dos conselhos municipais e estaduais de educação" (CAMPOS et al, 2011, p. 208). 
O novo Plano Nacional previsto para o decênio de 2010 a 2020, em suas novas diretrizes, apresenta como uma de suas metas a universalização do atendimento às crianças na faixa etária de quatro a cinco anos de idade na pré-escola.

Cabem aos cidadãos e instituições assegurarem que esses direitos sejam colocados em práticas em ambientes educacionais, a escola tem como tarefa sociopolítica auxiliar os indivíduos na formação e construção da consciência em relação ao lugar em que possa ter processo de fortalecimento da democracia e da humanização da sociedade. No entanto ao que parece, a questão maior é da legitimação dessa tarefa (SILVA, 2004, p. 81).

A gestão democrática, como princípio da educação, contribui para que se desenvolva uma educação de qualidade, que ajude a formar cidadãos participativos na sociedade e profissionais compromissados.

\section{Procedimentos metodológicos}

Trata-se de uma pesquisa de Abordagem Qualitativa. Essa abordagem foi escolhida por se tratar de um tema educacional, que envolve subjetividade e análise contextual. Ela não se afina há um esquema rígido de desenvolvimento, porém não significa que seja um trabalho improvisado.

Acerca de assunto, Gomes, Flores e Jimenéz (1996, p. 62) citam que os pesquisadores "quando realizam uma investigação qualitativa, nem sempre operam seguindo um esquema determinado, e quando tal esquema existe tão pouco é o mesmo para todos."

Apoiando inicialmente na pesquisa bibliográfica, recorreu-se a um discurso argumentativo, sendo assim, o pesquisador apresenta os principais conceitos, categorias e noções com as quais vai trabalhar, estabelecendo um diálogo com os autores.

Adentrar ao campo pesquisado é um momento prático da pesquisa, aquele em que se confirmam os pressupostos e hipóteses registradas no plano de investigação. Assim, delimitou-se um ambiente propício para o desenvolvimento da pesquisa, uma escola da rede municipal de Fortaleza, Ceará, que funciona com o ensino na Educação Infantil (4 e 5 anos), para compreendermos como acontece o seu desenvolvimento na prática e como se dar o funcionamento da gestão escolar na referida etapa de ensino.

Os sujeitos envolvidos nessa pesquisa foram duas componentes do núcleo gestor da escola (diretora e coordenadora) de uma escola de Educação Infantil localizada na 
cidade de Fortaleza. A escolha dos sujeitos se deu por atuarem como principais responsáveis pelo desenvolvimento da Gestão Escolar Democrática no estabelecimento de ensino.

Existiu assim, a necessidade de se apropriar da técnica de coleta de dados para melhor embasar a efetivação da presente pesquisa. Sendo a coleta de dados fundamental para desenvolver a pesquisa, optou-se pela elaboração de um questionário para realizar esse procedimento, com o intuito de comparar as informações com os estudos bibliográficos, propiciando conhecimentos.

Nesse sentido, a pesquisa caracteriza-se como exploratória, pois tem em seu objetivo fornecer critérios sobre a situação problema, possibilitando o surgimento de novas indagações que venham enriquecer a temática e levem a uma melhor compreensão do objeto de estudo.

$\mathrm{Na}$ fase analítica foi desenvolvida a investigação. Esta é a parte que contém um “conteúdo informativo acerca da realidade interna ou externa, aos sujeitos pesquisados, que serão usados como propósitos indagativos" (GOMES; FLORES; JIMENÉZ, 1996, p. 198).

Já na fase informativa, realiza-se a apresentação dos resultados. São os saberes que são produzidos, que são comunicados e socializados. Nela, se faz o empenho intelectual necessário para explicitar a compreensão de fatos do cotidiano.

A análise do questionário representa o elo entre teoria e a prática, onde se procura conhecer através de perguntas e respostas, a vivência da gestão na Educação Infantil. O questionário realizado foi entregue a profissionais da Educação que trabalham em uma instituição de Educação Infantil. A fim de fazer um "confronto" com o referencial teórico e através dele possamos conhecer algumas ações realizadas pela gestão nesses estabelecimentos de ensino.

\section{Análise e interpretação dos dados}

Realizou-se uma reflexão sobre a situação da gestão democrática em ambientes de Educação Infantil, alinhando à teoria a prática.

Desse modo, segue os resultados obtidos durante a pesquisa de campo que contou com a participação de uma coordenadora e uma diretora. 


\section{O que representa uma gestão democrática?}

A primeira questão está relacionada ao conceito de gestão. Conforme os dados da pesquisa perceberam-se nesta questão respostas com palavras diferentes, porém que chegam a um mesmo sentido, a uma mesma definição sobre Gestão Democrática, a qual se caracteriza como um trabalho desenvolvido com a participação de todos.

Segundo LUCK (2006, p. 36), A gestão escolar é caracterizada pelo reconhecimento da importância da participação consciente e esclarecida das pessoas nas decisões sobre a orientação, organização e planejamento do seu trabalho e articulação das várias dimensões e dos vários desdobramentos de seu processo de implementação.

Gestão Democrática aqui é compreendida como um processo no qual as pessoas atuam na escola, identificam problemas, discutem, deliberam, planejam, encaminham, acompanham, controlam e avaliam o conjunto de ações voltadas ao desenvolvimento da própria escola, na busca de soluções dos problemas que a escola tenha ou que venham a surgir. Esse processo é sustentado pela participação efetiva de todos os envolvidos na escola (comunidade escolar).

\section{Quais os benefícios de se adotar uma Gestão Democrática?}

A segunda pergunta trata dos benefícios de se adotar uma gestão democrática. A coordenadora ressalta como benefício o trabalho em equipe para a autonomia e a concretização dos objetivos almejados. A diretora descreve com outras palavras, porém, mantendo a mesma concepção, apontando que o principal benefício é a participação dos integrantes no processo educacional, onde todos se sentem envolvidos e responsáveis pelas ações desenvolvidas no ambiente escolar.

A lei $n^{\circ}$ 9.394/96 no Art. 14 estabelece que sistemas de ensino definirão as normas de Gestão Democrática de acordo com suas peculiaridades e com base nos princípios de participação dos professores na elaboração do projeto pedagógico da escola e a participação da comunidade escolar e local em conselhos ou equivalentes. E no Art. 15 asseguram aos sistemas de ensino a autonomia pedagógica, administrativa e financeira de acordo com as normas gerais do direito público financeiro.

Pode-se considerar a autonomia estabelecida pela referida lei anteriormente, como um beneficio adquirido pelo processo democrático e concluir que o processo de Gestão 
Democrática traz diversos benefícios para a comunidade escolar desde os respeito às normas coletivamente construídas, a garantia de amplo acesso dos sujeitos a informações da escola e a formação de educandos críticos, participativos, conhecedor das vivências sociais, ou seja, a escola democrática forma cidadãos consciente para atuar na sociedade.

\section{Quais as características que um Gestor democrático tem que ter?}

A terceira pergunta está relacionada às características de um gestor democrático, e mais uma vez percebemos uma relação próxima entre as mesmas. A Coordenadora aponta que o gestor democrático tem em sua principal função a responsabilidade de delegar, cobrar, agir e atender aos anseios do grupo. Já a Diretora acrescenta um pouco mais essas características quando relata que o gestor tem que ser: humilde, flexível e compreensível e que deve ter a capacidade de dialogar e conduzir seu trabalho com assiduidade, participação, moral e ética.

Um gestor democrático vai além de controlar e fiscalizar ele é:

Um gestor da dinâmica social, um mobilizador, um orquestrador de atores, um articulador da diversidade para dar unidade e consistência, na construção do ambiente educacional e promoção segura da formação de seus alunos (LUCK, 2000, p. 16).

Ou ainda...

O diretor coordena, mobiliza, motiva, lidera, delega aos membros da equipe escolar, conforme suas atribuições específicas, as responsabilidades decorrentes das decisões, acompanha o desenvolvimento das ações, presta contas e submete à avaliação da equipe o desenvolvimento das decisões tomadas coletivamente (LIBÂNIO; OLIVEIRA; e TOSCHI, 2007, p. 335).

Por fim, percebe-se que o gestor democrático, preocupe-se e se interessa pelo aprendizado dos alunos; estabeleçam metas claras a serem atingidas, envolva a equipe no planejamento, dar autonomia nas ações e sabe faz da gestão uma aprendizagem para a vida escolar, assim como para a sociedade no geral. 
Qual o papel do gestor escolar na Educação Infantil? No papel está oculta sua representatividade enquanto figura na dinâmica da escola?

A quarta pergunta refere-se sobre o papel do gestor escolar na Educação Infantil. Sobre isso ambas se referem a aprendizagem das crianças, entendendo que parte do interesse e da participação dos responsáveis pelo desenvolvimento integral das mesmas.

A Coordenadora descreve o papel do gestor como aquele que faz acontecer o processo de cuidar e educar de forma indissociável, que deve trabalhar a afetividade como o sucesso para a aprendizagem. Seguindo, a Diretora avança nas suas considerações, quando fala que o gestor da Educação Infantil é o responsável pela abertura da criatividade dentro de uma dinâmica recíproca dos envolvidos. Ele é o responsável diretamente pela transformação e construção de uma escola aberta para o novo. Com relação à representatividade do gestor no papel, não se percebeu uma resposta clara nas entrevistadas.

Conforme Lück (2006) o gestor tem grande importância na gestão administrativa, pois ele é o responsável pela parte física e institucional da escola, sendo suas especificidades enunciadas no plano escolar, bem como no regimento. Dentre as atribuições do gestor neste nível estão: a organização geral da instituição escolar, a relação da gestão com a comunidade internar e externa, a participação de ambas no planejamento, administração e avaliação da escola, a democratização das informações e por fim, a gestão do material e do patrimônio material.

O gestor democrático aqui é conceituado como representante legal da administração e da ordem escolar tem que apresentar uma visão global da instituição de ensino com foco na aprendizagem dos educandos. Ele é o responsável por providenciar as condições necessárias à aprendizagem, zelando pelo uso dos espaços, cuidando da administração dos recursos financeiros e melhorando as relações interpessoais da comunidade escolar. Lembrando que seu trabalho é compartilhado com os demais envolvidos no processo educacional.

Quais os principais desafios encontrados para consolidar uma gestão democrática em ambientes de Educação infantil? E sobre a comunidade? E sobre a autonomia. Existe? 
A quinta e última pergunta é sobre os desafios encontrados para se consolidar uma gestão democrática na Educação Infantil, em relação à comunidade e a autonomia do espaço educacional.

Sobre isso a Coordenadora afirma que as condições físicas dos prédios, a falta de funcionários para exercer algumas funções, assim como, profissionais capacitados para exercerem bem o seu trabalho são fatores que tem dificultado da instituição e que a comunidade precisa ser mais participativa, cobrando os seus direitos junto aos órgãos públicos por melhores condições de trabalho para os profissionais que atuam na instituição escolar. Cita também que os pais conhecem seus direitos, porém, não busca formas para efetivá-los. E por fim, fala que a autonomia da escola existe, porém, é mal administrada.

A Diretora relata que existem muitos desafios, porém não relatados, e que eles existem por que as pessoas não se sentem sujeitos das ações, preferindo ficar isento de seus deveres, ou seja, na morbidez como ela cita. Em relação à comunidade, relata que ela deve ser mais informada sobre seus deveres para que possam ter mais noção dos seus deveres e direitos e sair do comodismo. A autonomia para ela é algo que precisa ser revisto, dentro da gestão escolar, pois segundos a mesma é algo que talvez não exista, e se existe é só em algumas situações.

O Art. 15 da LDBEN 9394/96 estabelece que:

Os sistemas de ensino assegurarão às unidades escolares públicas de educação básica que os integram progressivos graus de autonomia pedagógica e administrativa e de gestão financeira, observadas as normas gerais de direito financeiro público.

O que se percebeu é que apesar da autonomia nos estabelecimentos de ensino ser um direito constitucional ela ainda não está bem esclarecida pelas entrevistadas, ocasionando o não usufruto integralmente da mesma e gerando mais um desafio ser superado.

A autonomia é a conquista que ocorre mediante um processo de humanização que exige liberdade para que apareça com responsabilidade. Não basta querer que a unidade escolar se torne autônoma e nem mesmo autorizá-la, mediante decretos, a isso. É necessário investir recursos na formação de sujeitos coletivos que possam assumir o comando dessa autonomia (SILVA, 1996, p.117). 
Então se faz necessário não só documentos legais, mas uma Formação Continuada para que os gestores possam gerir com autonomia as instituições escolares, contribuindo efetivamente para a promoção de uma educação de qualidade na Educação Infantil.

Portanto, a participação da comunidade escolar no processo de tomada de decisão, na construção coletiva dos objetivos e das práticas escolares, no diálogo e na busca de consenso deve se fazer presente no cotidiano das unidades de Educação Infantil.

\section{Considerações finais}

Com os resultados da pesquisa, visamos contribuir para a conscientização sobre a importância do desenvolvimento da gestão democrática nas instituições de Educação Infantil.

Sendo assim, com base no levantamento dos estudos podemos concluir que Gestão Democrática se caracteriza com a participação de todos os envolvidos nas instituições, que nesse caso podemos chamar de comunidade escolar. Fazer com que todos participem efetivamente é um dos grandes desafios da sociedade contemporânea.

A Educação Infantil, primeira etapa da Educação Básica, para crianças de 0 a 5 anos de idade, vem sendo administradas em instituições coletivas públicas ou privadas, nomeadas creches e pré-escolas e, compartilhada com a família. Tem caráter obrigatório na pré-escola e se apresenta como opção da família em creches. Ela vem passando por diversas transformações que visam beneficiar essa modalidade da educação. Porém, os significativos avanços não são garantia de implantação de uma educação de qualidade.

A Educação Infantil apresenta, em sua totalidade, diversos desafios que tem dificultado a implantação de uma educação de qualidade nesses ambientes educacionais. A contradição entre o que está escrito ou previsto nas leis e normas do país, com o que está sendo praticado só tem contribuído cada vez mais para aumentar a desigualdade das condições econômicas e do usufruto dos direitos.

É preciso uma gestão nas escolas de forma democrática, com qualidade, para que se faça cumprir os direitos das crianças se desenvolverem de forma integral em seus aspectos físicos, psicológicos, intelectual e social.

Portanto, quando se afirma que a gestão democrática é a melhor forma de execução, precisa-se analisar como estão sendo operacionalizadas e organizadas as 
ações, pois a instituição escolar tem que ter uma concepção ímpar das atitudes, objetivamente falando da comunidade e da família dentro da comunidade escolar. No entanto, devem existir características pontudas politicamente democráticas dentro da instituição escolar, por parte dos docentes, discente, funcionários, comunidade e família, resgatando propriamente a etimologia das palavras Educação Infantil, escola e democracia na sua gênese.

\section{Referências}

BRASIL. MEC Diretrizes Curriculares Nacionais para a Educação Infantil. Resolução n. 5 de 17 de dezembro de 2009. Secretaria de Educação Básica. Brasília: A Secretaria, 2010.

BRASIL. MEC. Plano de Desenvolvimento da Educação - PDE: Razões Princípios e Programas. Governo Federal. 2010.

BRASIL. MEC. Lei de Diretrizes e Bases da Educação Nacional - LDBEN 9394/96. Secretaria de Educação Básica. Brasília: A Secretaria, 1996.

BRASIL. MEC. Lei n 9.394/96, de 20 de dezembro de 1996. Estabelece as Diretrizes e Bases da Educação Nacional - LDBEN - Diário Oficial da União, Brasília, 10 de jan. 2001.

BRASIL. Lei ${ }^{\circ} 12,796$, de abril de 2013. Altera a Lei no 9.394, de 20 de dezembro de 1996, que estabelece as diretrizes e bases da educação nacional, para dispor sobre a formação dos profissionais da educação e dar outras providências. Disponível em: < http://www.educacao.saobernardo.sp.gov.br/images/Secoes/SE3222/Abril2013/Lei_Fed eral_12796-13> Acesso em: 12 de maio de 2013.

BRASIL. Lei ${ }^{\circ}$ 11.494, de 20 de junho de 2007. Regulamenta o Fundo de Manutenção e Desenvolvimento da Educação Básica e de Valorização dos Profissionais da Educação (FUNDEB), de que trata o art. 60 do ato das Disposições Constitucionais Transitórias; altera a Lei $\mathrm{n}^{\circ} 10.194$, de 4 de fevereiro de 2001; revoga disposições das Leis $\mathrm{n}^{\circ}$ 9.424, de 24 de dezembro de 1996, 10.880, de 9 de junho de 2004, e 10.845, de 5 de março de 2004; e da outras providencias. Diário Oficial da União, Brasília, 21 de jun.. 2007.

BRASIL. Constituição (1988). Constituição da República Federativa do Brasil. Brasília: Senado Federal, 1988.

BRASIL. Conselho Nacional de Educação. Resolução CNE/CEB n ${ }^{\circ} 7$ de 19 de abril de 2007. Que trata da consulta com bases nas leis $n^{\circ} 11.114$ de 2005 e $n^{\circ} 11274$, de 2006 , que se referem ao ensino fundamental de nove anos e à matricula obrigatória de crianças de seis anos de idade no ensino fundamental. Diário oficial da União, Brasília, 9 de jul. de 2007.

BRASIL. Conselho Nacional de Educação. Resolução CNE/CEB n ${ }^{\circ} 5$ de 17 de dezembro de 2009. Fixa as Diretrizes Curriculares para a Educação Infantil. Diário oficial da União, Brasília, 2009. 
BRASIL. Coleção PROINFANTIL, módulo III, volume 2 , unidade 1. MEC: Brasília, 2006a.

BRASIL. Coleção PROINFANTIL, módulo IIl, volume 2, unidade 2. MEC: Brasília, 2006b.

BRASIL. Coleção PROINFANTIL, módulo IIl, volume 2, unidade 5. MEC: Brasília, $2006 \mathrm{c}$.

BRASIL. Coleção PROINFANTIL, módulo I, volume 2 , unidade 1. MEC: Brasília, 2005a.

BRASIL. Coleção PROINFANTIL, módulo I, volume 2 , unidade 2. MEC: Brasília, 2005b.

BRASIL. Coleção PROINFANTIL, módulo I, volume 2 , unidade 4. MEC: Brasília, 2005c.

BRASIL. Coleção PROINFANTIL, módulo I, volume 2 , unidade 7. MEC: Brasília, 2005d.

BRASIL. Coleção PROINFANTIL, módulo I, volume 2 , unidade 8. MEC: Brasília, $2005 \mathrm{e}$.

CAMPOS, M. M.; COELHO, R.; NASCIMENTO, M. L. As politicas e a gestão da educação infantil. Revista Retratos da Escola. Dossiê Educação Infantil. CNTE. v. 5, n.9, p. 201-214, jul./dez. de 2011.

CURY, C. R. J. Legislação educacional brasileira. Rio de Janeiro: DP\&A, 2002.

FARIA, A C; CUNHA, I; FELIPE, Y X. Manual prático para elaboração de monografia. (Trabalhos de Conclusão de Curso, Dissertação e Teses). São Paulo: USTJ, 2002.

FREIRE, P. Professora sim, tia não: cartas a quem ousa ensinar. 6 ed. São Paulo: Olho D'Água, 1995.

GOMEZ, G R; FLORES, J; JIMÈNEZ, E. Metodologia de la investigacion Ccalitativa. Malaga: Ediciones Aljibe, 1996.

KUHLMANN J. M. Infância e educação infantil: uma abordagem histórica. Porto Alegre: Mediação, 1988.

LIBÂNEO, J. C. Organização e gestão da escola: teoria e prática. 5 ed. Goiânia: Alternativa, 2004.

LIBÂNEO, J. C.; OLIVEIRA, J F.; TOSCHI, M. S. Educação escolar: políticas, estrutura e organização. São Paulo: Cortez, 2007.

LIMA, L. Organização Escolar e Democracia Radical: Paulo Freire e a governação democrática da escola pública. São Paulo Cortez, 2000. 
LÜCK, H. et al. A escola participativa: o trabalho do gestor escolar. 4 ed. Rio de Janeiro: DP\&A, 2000.

LÜCK, H. Concepções e processos democráticos de gestão educacional. Petrópolis, RJ: Vozes, 2006.

MARSHALL, T. H. Cidadania, classe social, status. Rio de Janeiro: Zahar, 1967.

MINAYO, M. C. S. (Org.) O desafio de conhecimento. Pesquisa qualitativa em saúde. 11 ed. São Paulo: Hucitec, 2008.

NUNES, M. F. R.; CORSINO, P.; DIDONET, V. Educação Infantil no Brasil: primeira etapa da educação básica. Brasília: UNESCO, MEC/SEB, Fundação Orsa, 2011.

OLIVEIRA, D. A. (Org). Gestão Democrática da Educação: Desafios Contemporâneos. Rio de Janeiro: Vozes, 1997.

PREFEITURA DE RECIFE SECRETARIA DE EDUCAÇÃO. Educação Infantil: Ponte de Cidadania. V.6. Recife, 2004.

SAVIANI, D. Escola e democracia. 41 ed. Revista. São Paulo: Autores associados, 2009.

SILVA, J. M. A autonomia da Escola Pública. 3 ed. Campinas/SP. Papirus, 1996. (Coleção Práxis).

SILVA, P. S. Dialogando com a escola. In: (Ana Maria Bezerra de Almeida, Maria Socorro Lucena Lima e Silvina Pimentel Silva): Gestão democrática compartilhada na escola, um caminho que se constrói. 2 ed. Fortaleza: Edições Demócrito Rocha. 2004. cap. 9, p. 79-90.

TOURAINE, A. Igualdade e diversidade: o sujeito democrático. Trad. Modesto Florenzano. Bauru/SP: Edusc, 1998.

VEIGA, C. G. Infância e modernidade: ações, saberes e sujeitos. In: FARIA FILHO, Luciano Mendes (Org.). A infância e sua educação: materiais, práticas e representações. Belo Horizonte/MG: Autêntica, 2004. p. 35-82.

VIEIRA, L. F. Obrigatoriedade Escolar na Educação Infantil. Revista Retratos da Escola. Dossiê Educação Infantil. CNTE. v. 5, n.9, p. 245-262, jul./dez. de 2011.

YIN, R. K. Estudo de caso: planejamento e métodos. 2 ed. Porto Alegre: Bookman, 2001. 


\section{Como referenciar este artigo}

NASCIMENTO; Leandra Fernandes do.; CAVALCANTE, Maria Marina Dias. Gestão democrática na educação infantil. Revista on line de Política e Gestão Educacional, Araraquara/SP, v.21, n.01, p. 190-214, 2017. Disponível em: <http://dx.doi.org/10.22633/rpge.v21.n.1.2017.9991>. ISSN: 1519-9029.

Submetido em: 30/11/2016

Aprovado em: 30/03/2017 